\title{
Knowledge, Attitude and Willingness for Eye Donation in General Population of Odisha inEastern India
}

\author{
Suchitra Panigrahi ${ }^{1},{ }^{*}$ Bandana Rath ${ }^{2}$, Rama Kristna Sahu ${ }^{3}$ Sadananda Rath, ${ }^{4}$ \\ Santosh Kumar Sethi, ${ }^{5}$ Kasturi Mahapatra ${ }^{6}$ \\ ${ }^{1}$ Assistant Professor, Dept. Of Ophthalmology, MKCG Medical College And Hospital, Berhampur,Odisha, \\ India) \\ ${ }^{2}$ Associate Professor, Dept. Of Pharmacology, M.K.C.G. Medical College, Berhampur,Odisha, India) \\ ${ }^{3}$ Associate Professor Dept. Of Anatomy, M.K.C.G. Medical College, Berhampur,Odisha) \\ ${ }_{4}^{4}$ (Professor And HOD, Dept. Of Anatomy, M.K.C.G. Medical College, Berhampur,Odisha) \\ ${ }^{5}$ (Assistant Professor, Dept. Of Ophthalmology, MKCG Medical College And Hospital, Berhampur,Odisha, \\ India) \\ ${ }^{6}$ (Resident, Dept. Of Ophthalmology, MKCG Medical College And Hospital, Berhampur,Odisha, India) \\ *Corresponding author: Bandana Rath *
}

\begin{abstract}
Aim: To assess the knowledge,attitude and willingness of general population towards eye donation which includes patients and their attendants attending the outpatient department of a tertiary care medical college hospital of southern Orissa, Eastern India.

Materials and methods: 452 participants were administered a pretested semi-structured questionnaire. Chisquare test was used to determine the factors associated with willingness towards eye donation. Data was analysed using Graphpad prism version 7.0

Results: In this study 247(54.6\%) participants were willing to pledge for eye donation, there was significant association of willingness to donate eyes among males159 (64.1\%), among participants below 40 years of age175 (75.2\%),participants with higher education statusl46 (82.9\%) and urban population147 (70.6\%) .Perceived reasons among 205 (45.3\%) who were not willing to pledge were,137(66.8\%) need more information regarding eye donation,52(25.3\%) thought family may not allow for eye donation and 16(7.8\%) participants did not want to pledge due to religious disbelief.Media played a major role in creating awareness for eye donation.
\end{abstract}

Conclusion:Multipronged innovative strategies should be adopted to increase the awareness regarding eye donation in less educated and rural population.

Keywords: Eye donation, Awareness, Education, Unwillingness, Willingness to donate,

\section{Introduction}

With 7.8 million blind people in India, the country accounts for 20 per cent of the 39 million blind population across the globe, of which 1 per cent is on account of corneal blindness ${ }^{[1,2]}$ Corneal transplantation remains a major treatment option for restoring sight among those suffering from corneal blindness. This, however, is dependent on people willing to pledge for eye donation, and relatives willing to honour that pledge upon the death of the person. The number of corneal transplants done in India is far less than the actual requirement. This is largely due to the inadequate numbers of cornea collected. In India, corneal ulceration following xeropthalmia due to vitamin A deficiency, Ophthalmia neonatorum, ocular trauma, infectious keratitis, use of harmful traditional medicines and noxious substances,congenital corneal disorders like hereditary dystrophies, congenital glaucoma, peter's anomaly and other mesenchymal dysgenesis, birth trauma and metabolic disorders are important causes of childhood corneal blindness. In adults, the major causes of corneal blindness include bacterial, fungal or viral keratitis, hereditary cornealdystrophies, eye injuries, trachomatous keratopathy and corneal degenerations ${ }^{[1]}$.

The Andhra Pradesh eye disease study (APEDS) reported the prevalence of corneal blindness at $0.13 \%$ (95\% CI: 0.06-0.24), constituting 9\% of all blindness. APEDS also suggested a significant burden of corneal blindness in the rural population of Andhra Pradesh, of which 95\% was avoidable ${ }^{[3]}$. Although strategies to prevent corneal blindness are likely to be more cost-effective, visual rehabilitation by corneal transplantation remains a major treatment option for restoring sight in those who already have corneal blindness [4]. Approximately 18.7 million people are blind in India and 1, 90,000 are blind from bilateral corneal disease ${ }^{[5]}$.Every year another 20,000 join the list ${ }^{[6]}$. for the $x 1^{\text {th }}$ five year plan (2007-12) under the national program for control of blindness and visual impairment (NPCB), the government of India envisages achieving 
the goal of elimination of avoidable blindness in the country by the year 2020 by modification of existing schemes and introduction of new ones ${ }^{[7,8]}$. Besides other issues being addressed, corneal blindness is also targeted and eye banking activities are beingup-scaled through financial assistance to develop eye banks and eye donation centres ${ }^{[7]}$ After the first successful corneal transplantation by Edward Zirm, of Czechoslovakia, it has now become the most successful example of organ transplantation. With the understanding of corneal anatomy and physiology especially with regard to corneal endothelium, introduction of microsurgical technique, advances in corneal preservation and the upcoming of corneal immune suppressive agents, have resulted in a high success rate of corneal transplantation. The late Dr. Muthiah started the very first eye bank in Chennai in 1945 and he performed the first corneal transplant successfully in $1948{ }^{[7]}$. In India even after more than 60 years of performing corneal transplantation, a large no of patients are waiting for corneal transplantation. According to statistical data of NPCB, the current cornea procurement in India was 63256 corneas between 1st April 2016 to $31^{\text {st }}$ March 2017.Out of these, only $46 \%$ are utilized for sight restoration as the other $54 \%$ do not meet the standards for transplantation ${ }^{[5]}$. Based on our current ratio of suitable corneas, we would need 2 , 77,000 donations per year to perform 1, 00,000 corneal transplants in a year in India ${ }^{[6] . ~ S h o r t a g e ~ o f ~}$ transplantable corneas is common and has been the subject of much attention though there is approximately a 20 -fold increase in the donor eyes available now. To enhance the procurement of corneal donations further, raising the level of public education on eye donation was the most important first step ${ }^{[4]}$.It is necessary to gain increase in achievement of actual donations by suggesting eye donation to relatives of gravely ill or injured patients in ICU, causality, and trauma centre, by grief counselling after death ${ }^{[10,11,12]}$ Nearly 10 million $(9778$ 073)people die in India every year, sadly the corneal donation does not exceed more than a few thousand ${ }^{[13] .}$. The reasons for the very low number of eye donation in India are due to lack of awareness among the general public, absence of motivation even among trained personnel, social and religious myths, and many being not aware of the needs and benefits of eye donation. In the present scenario it is essential to enhance the awareness regarding eye donation among the potential donors in an effort to increase the procurement of corneas, recently which received much attention in our country with support and participation by the government and non-government organisations(NGOs) ${ }^{[4]}$.In our study we assessed the knowledge, attitude and willingness to donate eyes among the general population.

\section{Materials And Method}

We carried out this cross-sectional descriptive survey in the month of May 2017 among patientsattending the outpatient department (OPD) in a tertiary health care centre in Odisha. We included all individuals more than 18 years of age and those who were willing to participate. We excluded people with cognitive impairment and relatives of patients who were in need of corneas for transplantation. 485 people were asked to participate in our study, of them, $33(6.8 \%)$ declined due to lack of time and interest. Hence, our final sample had 452 people Informed consent was obtained from the participants. A structured questionnaire was used to elicit response $e^{4}$.Interviewers trained specifically for this study explained the questions in local language and noted the responses. Data collection instrument, the questionnaire was in four parts. The first part consisted of items about socio demographic details of the participants such as age, gender, education, religion, economic status, and place of residence. The second part intended to measure the knowledge level of participants about eye donation and the source of information. The third part consists of questions regarding their attitude towards eye donation, their willingness and unwillingness to donate their eyes and the reason behind pledging for eye donation and not pledging for eye donation. ${ }^{6}$ the participants willing to pledge were distributed with pledge forms to take signatures of their legal heirs. The ethical core committee of the hospital approved the study protocol. The researchers approached the participants and briefly explained the purpose of the study ${ }^{9}$.Written consent was obtained from the participants and they were given the freedom to quit the study at any time. Participants' confidentiality was respected. Descriptive (frequency, percentage, mean and standard deviation) and inferential (chi-square test and odds ratio) statistics were used to interpret the data. We used graph pad version 7.03 for statistical analysis.P values $<0.05$ were considered as minimum level of significance. 
III. Results

Table-I: Demographic profile of study participants $(\mathrm{n}=452)$

\begin{tabular}{|c|c|c|}
\hline Characteristics & $\begin{array}{c}\text { Total } \\
\text { No }\end{array}$ & Percentage (\%) \\
\hline Age & & 50.0 \\
$\geq 40$ & 226 & 50.0 \\
\hline Gender & 226 & 54.8 \\
\hline Male & 248 & 45.1 \\
\hline Female & 204 & \\
\hline Education & & 38.9 \\
\hline High qualified & 176 & 61.6 \\
\hline Low qualified & 276 & \\
\hline Location & & 32.5 \\
\hline Urban & 147 & 67.4 \\
\hline Rural & 305 & \\
\hline Religion & & 3.3 \\
\hline Hindu & 431 & 1.5 \\
\hline Christian & 7 & \\
Muslim & & \\
\hline
\end{tabular}

A total of 452 subjects participated in this study. The mean age was $39.019(\mathrm{SD} \pm 15.85$ years) with a range of 18 to 90 years. Out of 452 participants, 248(54.86\%) were males and 204(45.13\%) were females. $305(67.4 \%)$ participants belonged to rural area and 147 were from urban area. Majority of population belonged to Hindu community 431(95.3\%),15(3.3\%) were Christians and 7 (1.5\%)were muslims.176 (38.9\%) participants were with higher education status, among them 98 (21.6\%) passed higher secondary,55 (12.1\%)were graduates and $23(5.1 \%)$ were post graduates.276(61.6\%) candidates were less educated with qualification below secondary level which includes $190(42.03 \%)$ participants having education $7^{\text {th }}$ class, and $86(19.0 \%)$ participants below $7^{\text {th }}$ class.

Table-II: Response to the questionnaire on eye donation

\begin{tabular}{|c|c|c|}
\hline Response of the participants & $\begin{array}{c}\text { Total number of } \\
\text { respondents } \\
(452)\end{array}$ & $\begin{array}{c}\text { Percentage }(\%) \\
\text { of respondents }\end{array}$ \\
\hline Eyes can be donated after death & 262 & 57.9 \\
\hline $\begin{array}{c}\text { Ideal time to remove eyes within } 6 \text { hours of } \\
\text { death }\end{array}$ & 192 & 40.4 \\
\hline All age groups can donate eyes & 190 & 42.0 \\
\hline $\begin{array}{c}\text { Persons bearing spectacles, postcataract } \\
\text { surgery, hypertensive, diabetic can donate } \\
\text { eyes }\end{array}$ & 114 & 25.2 \\
\hline Only cornea is collected & 195 & 43.1 \\
\hline $\begin{array}{l}\text { Eye donation to restore vision in corneal } \\
\text { blindness only }\end{array}$ & 157 & 34.7 \\
\hline $\begin{array}{c}\text { No disfigurement of face because artificial } \\
\text { prosthesis given }\end{array}$ & 224 & 49.5 \\
\hline Identity of recipient not disclosed & 216 & 47.7 \\
\hline $\begin{array}{l}\text { Written consent of kin required before } \\
\text { collection of eyes from donor }\end{array}$ & 365 & 80.7 \\
\hline No monetary benefit to donor family & 283 & 62.6 \\
\hline $\begin{array}{l}\text { For eye donation one has to contact eye } \\
\text { bank \& knowledge regarding nearest eye } \\
\text { bank or eye collection centre. }\end{array}$ & 199 & 44.0 \\
\hline
\end{tabular}

In our study we found that Out of 452 participants,262(57.9\%) knew ,eyes can be donated after death.192(40.4\%)expressed that ideal time to remove eyes was within 6 hours of death.190(42.0\%) knew, all groups can donate their eyes.114(25.2\%) answered ,persons wearing spectacles, hypertensives, diabetics and post cataract surgery patients' can donate their eyes.195(43.1\%) knew that only cornea was collected for eye donation.157(34.7\%) knew that eye donation was done to restore vision in corneal blind people.224(49.5\%) told no disfigurement of face after eye donation, 216(47.7\%) knew that identity of recipient not disclosed.365(80.7\%) knew that written consent of the kin was required before collection of eyes from the donor.283(62.6\%) were 
aware that no monetary benefit was given to the donor family.199(44.0\%) responded that for eye donation one had to contact the nearest eye bank or eye collection centre.

TableIII: Different sources of information regarding eye donation

\begin{tabular}{|c|c|c|}
\hline Source of awareness & Total $(\mathbf{n}=\mathbf{4 5 2})$ & Percentage(\%) \\
\hline News paper & 174 & 38.4 \\
\hline Tv/internet/radio & 98 & 21.6 \\
\hline Wallpaints/posters/pamphlets & 56 & 12.3 \\
\hline Friends/relatives/neighbours & 124 & 27.4 \\
\hline
\end{tabular}

Among all,260 participants opined that eyes are to be donated after death. Regarding sources of information they got, participants wrote that they read about eye donation in newspapers $(n=174,38.4 \%)$, television internet and radio $(\mathrm{n}=98,21.6 \%)$, from wall paints, posters and other publicity campaigns like eye bank activities $(\mathrm{n}=56$, $12.3 \%)$ and from friends, relatives, neighbours $(n=124,27.4 \%)$.

Table IV: Factors associated with willingness to donate eyes

\begin{tabular}{|c|c|c|c|c|c|c|c|c|}
\hline Characteristics & & $\begin{array}{c}\text { Total } \\
(n=452)\end{array}$ & $\begin{array}{c}\text { Willingness } \\
\quad(n=247)\end{array}$ & $\begin{array}{c}\text { Percentage } \\
\%\end{array}$ & $\begin{array}{l}\text { Odds } \\
\text { ratio }\end{array}$ & $\begin{array}{c}95 \% \\
\text { confidence } \\
\text { interval } \\
\text { lower }\end{array}$ & $\begin{array}{c}95 \% \\
\text { confidence } \\
\text { interval } \\
\text { upper }\end{array}$ & p value \\
\hline \multirow{2}{*}{$\operatorname{Age} \operatorname{group}(y r s)$} & $<40$ & 226 & 170 & 75.2 & \multirow{2}{*}{5.874} & \multirow{2}{*}{3.865} & \multirow{2}{*}{8.814} & \multirow{2}{*}{$<0.0001$} \\
\hline & $\geq 40$ & 226 & 77 & 34.0 & & & & \\
\hline \multirow{2}{*}{ Gender } & Male & 248 & 159 & 64.1 & \multirow{2}{*}{2.355} & \multirow{2}{*}{1.597} & \multirow{2}{*}{3.449} & \multirow{2}{*}{$<0.0001$} \\
\hline & Female & 204 & 88 & 43.1 & & & & \\
\hline \multirow[b]{2}{*}{ Education } & $\begin{array}{c}\text { Highly } \\
\text { educated }\end{array}$ & 176 & 146 & 82.9 & \multirow[b]{2}{*}{8.432} & \multirow[b]{2}{*}{5.251} & \multirow[b]{2}{*}{13.28} & \multirow[b]{2}{*}{$<0.0001$} \\
\hline & $\begin{array}{c}\text { Less } \\
\text { educated }\end{array}$ & 276 & 101 & 36.6 & & & & \\
\hline \multirow{2}{*}{ Locality } & Urban & 147 & 103 & 70.1 & \multirow{2}{*}{5.647} & \multirow{2}{*}{3.622} & \multirow{2}{*}{8.85} & \multirow{2}{*}{$<0.0001$} \\
\hline & Rural & 305 & 113 & 37.0 & & & & \\
\hline
\end{tabular}

In our study we looked at the association of age, gender, educational status and locality with willingness for eye donation. Out of 452 participants , 56.6\%(247) willing to donate their eyes, 75.2\%(170) were below 40 years age group, 64.1\%(248) were males and 82.9\%(101) were with higher education and $70.1 \%$ were from urban area. Odds ratio showed that willingness to pledge for eye donation was significantly low in participants with age more than 40 years $(n=77,34 \%)$, in females $(n=77,43.1 \%)$, in less educated participants $(n=101,36.6 \%)$ and in participants of rural area $(n=305,37 \%)$. The main motivation force to donate eyes was due to pleasure to help the blind in60.3\%(149) and nobility in the act in $39.6 \%$ (98).

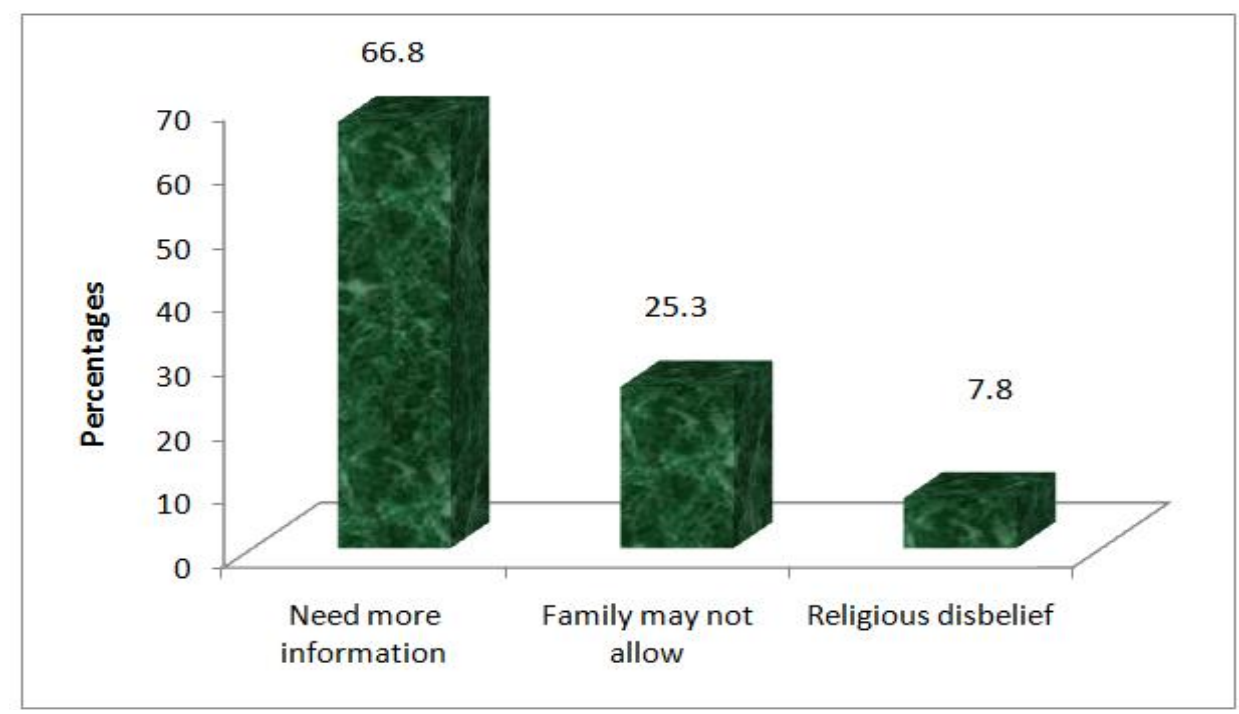

Fig-1: Reasons for unwillingness of participants for eye donation 
The reasons listed for unwillingness to donate eyes include, out of 205 (20.7\%) participants not willing to donate their eyes, $66.8 \%(137)$ wrote that they need more information regarding eye donation, $25.3 \%$ (52) participants thought family may not allow for eye donation and $7.8 \%(16)$ participants did not want to pledge due to religious disbelief that they may born blind in next birth because of eye donation.

\section{Discussion}

The present study highlighted the difference in knowledge,attitude and willingness regarding eye donation with relation to education status, age, gender and locality.In our study $57.9 \%(262)$ participants were aware that eyes can be donated after death which is low in comparison to studies done by Ronaki et al $(80.3 \%)$,Marthe et al $(80.3 \%)$, Bhandary et $\mathrm{al}(88 \%)^{[9,14,15]}$, whereas it is almost similar to the studies conducted by Goerge et al(49\%), Shrivastava et al $(53.4 \%)^{[16,17]}$. In our study, $40.4 \%(192)$ knew the ideal time limit of eye donation was within 6 hours of death, which is in accordance with that of Patil et al(36.5\%), Marathe et $\mathrm{al}(44.7 \%)$ Tiwari et al, $(50 \%),{ }^{[6,14,18]}$ whereas it is low in comparison to the observations of Bhandarey et al $(88 \%)^{\prime}$ Goerge et al(79.5\%) ${ }^{[15,16]}$.It is important for the general public to be aware of the time limit for eye donation after death,as eyes can not be utilised for optical purpose that are donated after 6 hours of death. (Table-II)

43.1\%(195) of our participants thought that eye donation means removal of cornea which is similar to the study done by Ronaki et al(54.9\%).$^{[9]} 49.5 \%$ ( 224) knew that eye donation does not cause disfigurement as artificial prosthesis was given after collection of cornea which is similar to the study by Patil et al $(39 \%),{ }^{[6]}$ Lawlor et $\mathrm{al}^{[19]}$ and low in comparison to Ronaki et al $(73.5 \%)$ and Bhandary et al $(76.2 \%){ }^{[9,15]}$

43.1\%(195)were aware that spectacle users, diabetics, hypertensives and post cataract surgery persons can donate their eyes, which is similar to the study of Ronaki et al(45.4\%).${ }^{[9]}$ The attitude behindeye donation were pleasure to help the blind to get vision in $60.3 \%$ (149) and the feeling of nobility in the act to help the community after death in $39.6 \%$ (98), which is similar to the studies done by Ronaki et al andGupta et al. ${ }^{[9,20]}$

Our observations revealed that 44\% (199) respondents knew that eye bank should be contacted for eye donation and there is an eye bank in our medical college hospital, in a study conducted by Ronaki et al $57.5 \%$ respondents knew about this. ${ }^{[9]}$

In our study $75.2 \%$ (170) respondents aged below 40 years are willing to donate their eyes, which is similar to the studies conducted by Patil et al $77.6 \%$,by Gupta et al $80 \%$,Singh et al $(87.2 \%)^{[6,20,21]}$. But it is low $(44.3 \%)$ inthe study of Tandon et al.and Yew et al $(67 \%)^{[22,23]}$. Our study found significantly low willingness to donate eyes in higher age group 34\%(77), which is similar to that of Priyadarhini et al ${ }^{[4]}$ In contrast,Patil et al and Ronaki et alfound willingness for eye donation is high in higher age group. ${ }^{[6,9]}$ The high willingness among younger age group observed in this study was probably due to more education level and more awareness due to high exposure to massmedia.

$64.1 \%$ ( 248) malesof all participants were willing to donate their eyes, whereas there is significantly low $43.1 \%$ ( 204) willingness to donate eyes among females, which corroborates with that of Priyadashini et al, Patil et al, Ronaki et al,Marathe et al and Shinde et al ${ }^{[4,6,9,14,24]}$ While there is no association found between genders by Srivastav et al. ${ }^{[17]}$ Lower willingness among females may be the necessity to seek permission from their family members. In our observation, $82.9 \%$ of participants with higher education were willing to donate their eyes which are significantly lower than participants with lower education status. Similar results were shown in studies done by Ronaki et al, Marathe et al. ${ }^{[9,14]}$ No association with education and willingness was noted by Patil et al and Bhandare et al. ${ }^{[6,15]}$ ( Table-IV)In the present study $70.6 \%(103)$ participants belonging to urban area were willing to donate their eyes, whereas only37\% (113) participants from rural area were willing to donate their eyes, it was similar to the studies done by Priyadarshini et al, Ronaki et al. ${ }^{[4,9]}$

Lack of essential knowledge regarding eye donation could be possible barriers for unwillingness to donate eyes. These important issues can be targeted in future campaigns meant to create awareness in eye donation. The major source of awareness in our study was from newspapers, television, from friends, relatives and neighbours, from wall paints, posters,pamphlets and activities by eye bank. Other studies alsomentioned similar sources of information regarding awareness. ${ }^{[4,6,9]}$

Data from our study suggests that multi-pronged approach to be developed to increase the awareness among people with lower educational status, rural population, females and elder age group.The major proportion of current awareness of eye donation has been through publicity campaigns by non-government organisations(NGOs) and campaign by government agencies through television, newspapers,radio, posters,pamphlets and wall paints .These are probably not sufficiently effective for the target population .Prominent display boards at hospitals and community gathering places can increase the awareness and knowledge of target population. 


\section{Conclusion}

A major group of people who are unwilling to donate their eyes need more information regarding eye donation, many hadreligious disbeliefs also. Social media can play a major role in creating awareness regarding eye donation. Personal approach by health personnel's to motivate public for eye donation should be given emphasis. Kin who donated the eyes of their family members earlier can act as motivators to spread positive thought and to removemyths associated with eyedonation. Grief counsellors, priests and community leaders can be used as catalysts to promote eye donation in families where death has already occurred.A great deal of motivational programmes is required to convert the awareness to willingness.

\section{References}

[1]. Gupta N, Tandon, Gupta SK, Sreenivas V, Vashist P. Burden of corneal blindness in india. Indian J Community Med. 2013;38(4):198-206.

[2]. Neena J, Rachel J, Praveen V, Murthy GV. Rapid assessment of avoidable blindness Indian study. Plos one 2008; 3(8):e2867

[3]. Dandona L, dandona R, Srinivas M, Giridhar P, Vilas K, Prasad MN, John RK, Mccarty C A, Rao G N. Blindness in the Indian state of Andhra Pradesh. Invest Ophthalmol vis sci 2001; 42(5):908-916

[4]. Priyadarshini B, Srinivasan M, Padmavathi A, Selvam S, Saradha R, Nirmalan PK. Awareness of eye donation in an adult population of Southern India. A pilot study. Indian J Ophthalmol 2003; 51(1):101-104.

[5]. npcb.statistics of 2016-17 of eye donation.available in http://www.npcb.in accessed on 26.6.2017.

[6]. Patil R, Gothankar J, Bhat P, Saluja J, Sane S. Eye donation: Awareness and willingness among shopkeepers. Int J Community med public health $2017 ; 4: 2056$

[7]. Vijayamahantesh.M., Bijapur, Vallabha K.Knowledge,attitude and practice pattern regarding eye donation,eye banking and corneal transplant in a tertiary care hospital. Journal of Krishna institute of medical sciences university(jkimsu) 2015; 4(4): 94-103

[8]. Dandona L, Dandona R, Naduvilath TJ, Mccarty C A.,Nanda A, Srinivas M. Is current eye care policy focus almost exclusively on cataract adequate to deal with blindness in india.Lancet.1998;351:1312-6

[9]. Ronaki V R, Sheeladevi S, Ramchandran B P, Jalbert I. Awareness regarding eye donation among stakeholders in Srikakulum district in south India. BMC Ophthalmol. 2014; 14:25 NPCB.statistics of 2016-17 of eye donation.

[10]. Pallavi Anil Uplap, Rashmi Singh. Exploring scope for improvement in knowledge attitude and practices about organ donation and transplantation among post graduate medical students in mumbai, India. International Journal of Community Medicine and Public health 2017;4(1):229-234

[11]. K. Chakradhar, D Joshi,B.Srikanth Reddy. Knowledge,attitude and practice regarding organ donation among Indian dental students. International Journal of organ transplantation medicine.2016;7(1):28-35

[12]. Poreddi Vijayalakshmi, T S Sunitha, Sailaxmi Gandhi. Knowledge,attitude and behaviour of the general population towards organ donation:an indian prospective. 2016; 29(5): 257-261

[13]. population statistics of 2016.Accessed on 30.62017

[14]. Marathe N, Chalisgaonkar C, Singh R. Awareness of eye donation in population of central India. J evolution med dent sci. 2014;3(64):14030-6.

[15]. Bhandary S, Khanna R, Rao K A, Rao L G, Lingam K D, Binu V. Eye donation - awareness and willingness among attendants of patients at various clinics in Melaka, Malaysia. Indian J Ophthalmol. 2011;59(1):41-5

[16]. George S, Mohan P. Awareness, knowledge and attitude regarding eye donation in Thiruvanantapuram district south India. Int J recent trends in sci tech. 2015;14(2):322-5.

[17]. Shrivastava S, Kulthe S B, Gore H D. Awareness of eye donation and willingness to donate eyes in population attending outdoor patients department of ophthalmology at SKNMC, Pune (Maharashtra). Indian J Applied Res. 2015;5(1):451-3

[18]. Tiwari R, Diwakar A, Marskole P, Bhargo L, Anwar D. A study to assess awareness on eye donation and willingness to pledge eyes for donation in adult population in Gwalior district (MP), India. Int J Res Med Sci. 2014;2(2):662-6.

[19]. Lawlor M, Kerridge I, Ankeny R, Dobbins T A, Billson F. Specific unwillingness to donate eyes: the impact of disfigurement, knowledge and procurement on corneal donation. Am J Transplant 2010; 10(3):657-663

[20]. Gupta A, Jain S, Jain T, Gupta K. Awareness and perception regarding eye donation in students of a nursing college in Bangalore. Indian J community med 2009, 34(2):122-125.

[21]. Singh M M, Rahi M, Pagare D, Ingle G K. Medical students' perception on eye donation in Delhi. Indian J Ophthalmol 2007; 55(1):49-53

[22]. Tandon R, Verma K, Vanathi M, Pandey R M, Vajpayee R B. Factors affecting eye donation from postmortem cases in a tertiary care hospital. Cornea 2004, 23(6):597-601.

[23]. Yew Y W, Saw SM, Pan J C, Shen H M, Lwin M, Yew M S, Heng W J. Knowledge and beliefs on corneal donation in singapore adults. Br J Ophthalmol 2005,89(7):835-840

[24]. Shinde S, Mundada R, WangikarV D. Awareness of eye donation in an urban population in Aurangabad, Maharashtra. Int J Recent trends sci tech. 2013;8(2):128-129

\footnotetext{
*Suchitra Panigrahi. "Knowledge, Attitude and Willingness for Eye Donation in General Population of Odisha inEastern India." IOSR Journal of Dental and Medical Sciences (IOSRJDMS) 16.7 (2017): 01-06
} 